\title{
ANALISIS PERSEPSI KUALITAS LAYANAN TERHADAP KEPUASAN PASIEN PUSKESMAS TERAKREDITASI AEK LOBA KABUPATEN ASAHAN
}

\author{
Analysis of Service Quality Perception on The Satisfaction of Accredited Health Center Aek Loba \\ Asahan District
}

\author{
Ibnu Yazid Shabri, Tarsyad Nugraha, Darwin Syamsul \\ Ilmu Kesehatan Masyarakat, Institut Kesehatan Helvetia \\ Email : ibnuyazidshabri@gmail.com
}

\begin{abstract}
As more and more health services are growing in the midst of society ranging from government to private property, thus making competition among health care institutions. The main problem that arises is that the service provided is in accordance with the expectations of the patient or not. This study aims to analyze and explain the causal influence between independent variables on the dependent variable. This type of research is descriptive analytical. Data were analyzed by conducting univariate, bivariate and multivariate tests. The logistic regression statistical test results showed that there was a positive effect of the manifestation variable $(\mathrm{sig}=0.019)$, reliability $(\mathrm{sig}=0.023)$, responsiveness $(\mathrm{sig}=$ $0.020)$, assurance $(\mathrm{sig}=0.015)$ and empathy $(\mathrm{sig}=0.017)$ on patient satisfaction. And the variable that has the greatest influence on patient satisfaction is the reliability variable with exp value (B) of 257396,374. The conclusion of this study is that all aspects of service quality in the form of aspects of manifestation, reliability, responsiveness, assurance and empathy affect patient satisfaction in the Aek Loba Accredited Health Center in Asahan Regency.

Keywords: patient satisfaction, service quality
\end{abstract}

\begin{abstract}
Abstrak
Seiring semakin banyak pelayanan kesehatan yang tumbuh ditengah-tengah masyarakat mulai dari milik pemerintah hingga swasta, sehingga menjadikan persaingan diantara lembaga pelayanan kesehatan. Masalah utama yang muncul adalah pelayanan yang diberikan apakah sudah sesuai harapan pasien atau belum. Penelitian ini bertujuan untuk menganalisis dan menjelaskan pengaruh kausal antara variabel independen terhadap variabel dependen. Jenis penelitian bersifat analitik deskriftif. Data dianalisis dengan melakukan uji univariat, bivariat dan multivariate. Hasil uji statistik regresi logistik menunjukkan bahwa ada pengaruh positif dari variabel keberwujudan (sig $=0,019$ ), keandalan $(\operatorname{sig}=0,023)$, daya tanggap $(\operatorname{sig}=0,020)$, jaminan $(\operatorname{sig}=0,015)$ dan empati $(\operatorname{sig}=$ 0,017 ) terhadap kepuasan pasien. Dan variabel yang paling besar pengaruhnya terhadap kepuasan pasien adalah variabel keandalan dengan nilai exp(B) sebesar 257396.374. Kesimpulan dari penelitian ini adalah seluruh aspek kualitas layanan berupa aspek keberwujudan, keandalan, daya tanggap, jaminan dan empati berpengaruh terhadap kepuasan pasien di Puskesmas Terakreditasi Aek Loba Kabupaten Asahan
\end{abstract}

Kata Kunci : Kepuasan pasien, kualitas layanan 


\section{PENDAHULUAN}

Pasal $28 \mathrm{H}$ ayat (1) UUD Negara Republik Indonesia Tahun 1945 menegaskan bahwa setiap orang berhak hidup sejahtera lahir dan batin, bertempat tinggal dan mendapat lingkungan hidup yang baik dan sehat serta berhak memperoleh pelayanan kesehatan. Untuk mencapai tujuan pembangunan kesehatan nasional diselenggarakan berbagai upaya kesehatan secara menyeluruh, berjenjang dan terpadu. Puskesmas adalah fasilitas pelayanan kesehatan yang menyelenggarakan upaya kesehatan masyarakat dan upaya kesehatan perseorangan tingkat pertama, dengan lebih mengutamakan upaya promotif dan preventif untuk mencapai derajat kesehatan masyarakat yang setinggi tingginya di wilayah kerjanya (Depkes RI, 2015). Ujung tombak dari penyelenggaraan pelayanan kesehatan untuk masyarakat di tingkat dasar di Indonesia adalah melalui Pusat Kesehatan Masyarakat (Puskesmas), apalagi dalam era Jaminan Kesehatan Nasional (JKN) dimana diberlakukan sistem rujukan berjenjang, pelayanan kesehatan akan difokuskan di Fasilitas Kesehatan Tingkat Pertama (FKTP) (Depkes RI, 2014).

Mutu pelayanan kesehatan sangat erat hubungannya dengan kepuasan penerima jasa pelayanan kesehatan dalam hal ini adalah pasien, karena kebanyakan penilaian para pengguna jasa pelayanan kesehatan lebih mementingkan proses pelayanan kesehatan dibandingkan outcom (Wardani, 2017). Layanan kesehatan yang bermutu adalah layanan kesehatan yang selalu berupaya memenuhi harapan pasien sehingga pasien akan selalu merasa berhutang budi serta sangat berterima kasih. Untuk menjamin bahwa perbaikan mutu, peningkatan kinerja dilaksanakan secara berkesinambungan, maka perlu dilakukan penilaian oleh pihak eksternal dengan menggunakan standar yang ditetapkan yaitu melalui mekanisme akreditasi (Depkes RI, 2015).

Supranto mengemukakan dimensi kualitas pelayanan terdiri dari : keandalan (reliability), daya tanggap (responsiveness), jaminan (assurance), empati (empahty) dan terukur (tangibel) (Supranto, 2006). Parasuraman juga mengemukakan bahwa konsep mutu layanan yang berkaitan dengan kepuasan pasien ditentukan oleh lima unsur yang biasa dikenal dengan istilah mutu layanan "SERVQUAL" (responsiveness, assurance, tangible, empathy dan reliability) (Valarie, dkk., 1996). Pohan menyatakan kepuasan pasien adalah suatu tingkat perasaan pasien yang timbul sebagai akibat dari kinerja layanan kesehatan yang diperoleh setelah pasien membandingkannya dengan apa yang diharapkan (Pohan, 2007).

Salah satu indikator keberhasilan pelayanan kesehatan adalah kepuasan pasien (Depkes RI, 2017). Mutu pelayanan kesehatan menunjukkan pada tingkat kesempurnaan pelayanan kesehatan dalam menimbulkan rasa puas pada diri setiap pasien. Makin sempurna kepuasaan tersebut, makin baik pula mutu pelayanan kesehatan (Depkes RI, 2017). Salah satu penyebab terjadinya ketidak puasan adalah masalah kualitas pelayanan. Bila kualitas pelayanan kesehatan tidak ditingkatkan, besar kemungkinan jumlah pasien akan menyusut. Faktor kepuasan pasien terhadap kualitas pelayanan kesehatan akan sangat mempengaruhi jumlah kunjungan pasien ke puskesmas tersebut. Hal itu akan membuat pasien menjadi merasa kecewa, dan akan menciptakan persepsi masyarakat tentang citra puskesmas yang tidak bisa memberikan kualitas pelayanan yang baik. Itulah alasan mengapa kualitas pelayanan itu sangat di perlukan dalam sebuah instusi kesehatan khusus nya puskesmas, untuk memberikan kepuasan kepada pasien (Aini, 2016). Untuk itu Sebagai pusat pelayanan kesehatan strata pertama di wilayah kerjanya, Puskesmas merupakan sarana pelayanan kesehatan yang wajib menyelenggarakan pelayanan kesehatan secara bermutu, terjangkau, adil dan merata (Trihono, 2005).

Kualitas pelayanan merupakan driver dari kepuasan pasien yang bersifat multi dimensi. Untuk mengetahui dimensi manakah yang penting dalam memengaruhi kepuasan pelanggan maka konsep Service Quality yang telah dikembangkan oleh Parasuraman, Berry dan Zeithaml dalam Irawan dapat dijadikan suatu acuan. Konsep tersebut memformulasikan 5 dimensi, yaitu keberwujudan (tangible), andal (reliability), ketanggapan (responsiveness), jaminan (assurance) dan empati (empathy) (Irawan, 2008). Lupiyoadi mengemukakan bahwa pasien dalam mengevaluasi kepuasan terhadap jasa pelayanan yang diterima mengacu pada beberapa faktor, yaitu: Kualitas jasa, Kualitas pelayanan, Faktor emosional, Harga Pelayanan, Biaya (Lupiyoadi, 2006). 


\section{BAHAN DAN METODE}

Penelitian ini merupakan penelitian kuantitatif yang bersifat analitik deskriftif yaitu penelitian yang bertujuan untuk menganalisis dan menjelaskan pengaruh kausal antara variable-variabel independen terhadap variabel dependen. Penelitian ini dilakukan di Puskesmas Aek Loba Kabupaten Asahan. Puskesmas Aek Loba Kabupaten Asahan berlokasi di Kecamatan Aek Kuasan Kabupaten Asahan. Adapun jumpah sampel sebanyak 100

Tabel 1. Hubungan Variabel Independen dengan Kepuasan Pasien di Puskesmas Terkareditasi Aek Loba Kabupaten Asahan

\begin{tabular}{|c|c|c|c|c|c|c|c|}
\hline \multirow{3}{*}{ Variabel } & \multicolumn{4}{|c|}{ Kepuasan Pasien } & \multirow{2}{*}{\multicolumn{2}{|c|}{ Jumlah }} & \multirow{3}{*}{$p$-value } \\
\hline & \multicolumn{2}{|c|}{ Tidak Puas } & \multicolumn{2}{|c|}{ Puas } & & & \\
\hline & $\mathbf{n}$ & $\%$ & $\mathbf{n}$ & $\%$ & $\mathrm{n}$ & $\%$ & \\
\hline \multicolumn{8}{|l|}{ Keberwujudan } \\
\hline Kurang & 1 & 20 & 4 & 80 & 5 & 100 & \multirow{3}{*}{0,000} \\
\hline Cukup & 0 & 0 & 59 & 100 & 59 & 100 & \\
\hline Baik & 0 & 0 & 36 & 100 & 36 & 100 & \\
\hline \multicolumn{8}{|l|}{ Keandalan } \\
\hline Kurang & 1 & 16.7 & 5 & 83,3 & 6 & 100 & \multirow{3}{*}{0,000} \\
\hline Cukup & 0 & 0 & 60 & 100 & 60 & 100 & \\
\hline Baik & 0 & 0 & 34 & 100 & 34 & 100 & \\
\hline \multicolumn{8}{|l|}{ Daya Tanggap } \\
\hline Kurang & 1 & 12,5 & 7 & 87,5 & 18 & 100 & \multirow{3}{*}{0,000} \\
\hline Cukup & 0 & 0 & 36 & 100 & 36 & 100 & \\
\hline Baik & 0 & 0 & 56 & 100 & 56 & 100 & \\
\hline \multicolumn{8}{|l|}{ Jaminan } \\
\hline Kurang & 1 & 16,7 & 5 & 83,3 & 6 & 100 & \multirow{3}{*}{0,000} \\
\hline Cukup & 0 & 0 & 41 & 100 & 41 & 100 & \\
\hline Baik & 0 & 0 & 53 & 100 & 53 & 100 & \\
\hline \multicolumn{8}{|l|}{ Empati } \\
\hline Kurang & 1 & 16,7 & 5 & 83,3 & 6 & 100 & \multirow{3}{*}{0,000} \\
\hline Cukup & 0 & 0 & 45 & 100 & 45 & 100 & \\
\hline Baik & 0 & 0 & 49 & 100 & 49 & 100 & \\
\hline Jumlah & 1 & 1 & 99 & 99 & 100 & 100 & \\
\hline
\end{tabular}

orang. Teknik pengambilan sampel secara accidental sampling, dimana pengambilan sampling responden yang secara kebetulan ada atau sampel yang tersedia saat penelitian (Notoatmodjo, 2005). Analisis data yang dilakukan adalah analisis univariat, bivariat dengan menggunakan uji chi-square dan multivariate dengan menggunakan uji regresi logistic berganda (Sastroasmoro dkk, 2008).

\section{HASIL DAN PEMBAHASAN}

Hasil uji statistik yang dilakukan pada tabel 1 menunjukkan bahwa terdapat pengaruh antara variabel Keberwujudan, Keandalan, Daya Tanggap, Jaminan, dan Daya tanggap dengan kepuasan pasien di Puskesmas terkareditasi Aek Loba Kabupaten Asahan yang mana hal ini ditunjukkan dengan nilai masing-masing $p$-value $=0,000<\mathrm{a}(0,05)$.
Untuk melihat adanya interaksi antara variable selanjutnya dilakukan uji interaksi. Hasil uji interaksi dapat dilihat pada tabel 2. Dari tabel 2 dapat dilihat bahwa nilai sig masing-masing variabel bebas $<0,05$, hal ini berarti seluruh variabel bebas saling berinteraksi dengan variabel terikat. Untuk melihat variabel bebas yang paling besar pengaruhnya terhadap variabel terikat adalah dengan melihat nilai exp(B). Pada tabel diatas dapat dilihat bawa variabel bebas yang mempunyai nilai $\exp (B)$ paling besar adalah variabel keandalan dengan nilai 257396.374, ini berarti variabel keandalan adalah variabel bebas yang paling besar pengaruhnya terhadap variabel terikat. Dari tabel 2 diperoleh model penelitian sebagai berikut :

Kepuasan Pasien $=-61.576+11.058$ (keberwujudan) +12.458 (keandalan) + 0.781 (daya tanggap) +10.624 (jaminan) +10.343 (empati) 
Tabel 2. Hasil Uji Interaksi

\begin{tabular}{lrccccr}
\hline Variabel & B & S.E. & Wald & Df & Sig. & Exp(B) \\
\hline Keberwujudan & 11.058 & 4729.438 & .000 & 1 & .019 & 63445.671 \\
Keandalan & 12.458 & 3907.259 & .000 & 1 & .023 & 257396.374 \\
Daya tanggap & .781 & 4675.842 & .000 & 1 & .020 & 2.183 \\
Jaminan & 10.624 & 4373.501 & .000 & 1 & .015 & 41089.666 \\
Empati & 10.343 & 4848.890 & .000 & 1 & .017 & 31035.554 \\
Constant & -61.576 & 8670.433 & .000 & 1 & .013 & .000 \\
\hline
\end{tabular}

Dari persamaan diatas dapat diketahui bahwa nilai koefisien regresi pada masing-masing variabel bernilai positif dimana nilai tersebut menunjukkan bahwa adanya hubungan yang searah antara keberwujudan, keandalan, daya tanggap, jaminan dan empati terhadap kepuasan pasien di Puskesmas Terakreditasi Aek Loba Kabupaten Asahan. Hubungan searah tersebut menggambarkan bahwa setiap kenaikan satu satuan pada variabel keberwujudan, keandalan, daya tanggap, jaminan dan empati akan menyebabkan tingkat kepuasan pasien sebesar 11.058 kali yang disebabkan oleh keberwujudan, 12,458 kali yang disebabkan oleh keandalan, 0,781 kali yang disebabkan oleh daya tanggap, 10,624 kali yang disebabkan oleh jaminan dan 10,343 kali yang disebabkan oleh empati. Sedangkan nilai negatif pada konstanta sebesar 61,576 menggambarkan bahwa tanpa adanya intervensi terhadap keberwujudan, keandalan, daya tanggap, jaminan dan empati. Sedangkan pada kepuasan pasien akan menurun sebesar 61,576 kali.

Tangibles (Keberwujudan) adalah kemampuan suatu perusahaan dalam menunjukkan eksistensinya kepada pihak eksternal. Penampilan kantor dan karyawan, kemampuan sarana dan prasarana fisik perusahaan (termasuk fasilitas komunikasi), serta lingkungan sekitarnya adalah bukti nyata dari pelayanan yang diberikan oleh pemberi jasa. Penampilan pelayanan tidak hanya sebatas pada penampilan fisik bangunan yang megah tetapi juga penampilan petugas dan ketersediaan sarana dan prasarana penunjang. Cara berpakaian dan berhias dari seseorang dapat menunjukkan kepribadian, sikap dan karakter seseorang. Petugas kesehatan yang memperhatikan penampilan dirinya agar selalu tampil bersih dan rapi dapat menimbulkan citra diri yang positif serta sikap profesionalisme. Begitu juga dengan penampilan fisik perawat dapat mempengaruhi persepsi pasien terhadap pelayanan yang diterima, karena tiap pasien mempunyai citra bagaimana seharusnya seorang perawat. Walaupun penampilan tidak sepenuhnya mencerminkan kemampuan perawat tetapi mungkin akan lebih sulit bagi perawat untuk membina rasa percaya terhadap pasien jika perawat tidak memenuhi citra pasien.

Hasil analisis data menunjukkan bahwa keberwujudan yang pada penelitian ini dinilai dari aspek kebersihan gedung dan lingkungan Puskesmas, sikap dan Penampilan petugas medis Puskesmas serta sarana dan prasarana pendukung yang dimiliki Puskesmas, keberwujudan (tangibles) mempunyai pengaruh positif terhadap kepuasan pasien di Puskesmas terakreditasi Aek Loba Kabupaten Asahan. Hal ini dapat diartikan jika keberwujudan meningkat maka kepuasan pasien di Puskesmas terakreditasi Aek Loba Kabupaten Asahan tentu akan meningkat pula.

Reliability atau keandalan yaitu kemampuan perusahaan untuk memberikan pelayanan sesuai yang dijanjikan secara akurat dan terpercaya. Reliability (keandalan) adalah kemampuan Puskesmas terakreditasi Aek Loba Kabupaten Asahan untuk memberikan pelayanan sesuai dengan yang dijanjikan secara akurat dan terpercaya. Keandalan pelayanan meliputi prosedur penerimaan pasien yang cepat dan tepat, prosedur pelayanan yang tidak menyusahkan pasien, pelayanan yang cepat tepat waktu serta petugas memberikan pelayanan yang bebas dari kesalahan. Hasil analisis data menunjukkan bahwa keandalan pelayanan (reliability) mempunyai pengaruh positif terhadap kepuasan pasien di Puskesmas terakreditasi Aek Loba Kabupaten Asahan. Penelitian yang dilakukan Muhammad A dan kawan-kawan yang menyatakan bahwa reliability (keandalan) berpengaruh positif terhadap kepuasan pasien. Semakin baik keandalan pelayanan yang diberikan tenaga medis akan semakin tinggi pula tingkat kepuasan pasien saat 
berobat. Begitu juga sebaliknya apabila keandalan pelayanan yang diberikan tenaga medis rendah maka tingkat kepuasan pasien saat berobat pun semakin rendah (Muhammad dkk, 2016).

Dalam penelitian ini variabel keandalan adalah variabel yang paling besar pengaruhnya terhadap kepuasan pasien. Dari pengamatan yang dilakukan adapun penyebab variabel keandalan menjadi variabel yang paling berpengaruh terhadap kepuasan pasien diantaranya adalah Dokter yang selalu ada pada jam pelayanan kesehatan sehingga pasien yang berobat ke Puskesmas terakreditasi Aek Loba Kabupaten Asahan bisa memastikan diri bertemu dengan Dokter untuk mengkonsultasikan penyakit yang dideritanya. Selain itu dalam menangani setiap pasien yang berobat ke Puskesmas terakreditasi Aek Loba Kabupaten Asahan Dokter telah melakukan proses penanganan sesuai dengan prosedur praktek pelayanan klinis.

Responsiveness, atau ketanggapan yaitu suatu kemauan untuk membantu dan memberikan pelayanan yang cepat (responsive) dan tepat kepada pelanggan, dengan penyampaian informasi yang jelas. Membiarkan konsumen menunggu tanpa alasan yang jelas menyebabkan persepsi yang negatif dalam kualitas pelayanan. Secara singkat dapat diartikan sebagai kemauan untuk membantu pelanggan dengan memberikan layanan yang baik dan cepat. Hasil analisis data menunjukkan bahwa daya tanggap pelayanan (Responsiveness) yang mempunyai pengaruh positif terhadap kepuasan pasien di Puskesmas terakreditasi Aek Loba Kabupaten Asahan. Pada penelitian yang dilakukan Noreti menyatakan bahwa daya tanggap berpengaruh positif dan signifikan terhadap kepuasan pasien. Semakin baik daya tanggap yang diberikan oleh dokter, bidan, perawat,tenaga medis lainnya di Puskesmas terhadap pasien akan semakin tinggi pula kepuasan pasien. Sebaliknya semakin tidak baik daya tanggap yang diberikan oleh dokter, bidan, perawat,tenaga medis maka semakin rendah pula kepuasan pasien. Pengaruh daya tanggap terhadap kepuasan pasien adalah semakin baik persepsi pasien terhadap ketanggapan petugas maka kepuasan juga akan semakin meningkat. Dan jika persepsi pasien terhadap daya tanggap petugas rendah maka kepuasan pasien juga akan rendah.

Assurance, atau jaminan dan kepastian yaitu pengetahuan, kesopan santunan, dan kemampuan para pegawai perusahaan untuk menumbuhkan rasa percaya pelanggan kepada perusahaan. Hasil analisis data ini menunjukkan bahwa jaminan pelayanan (assurance) mempunyai pengaruh positif terhadap kepuasan pasien di Puskesmas terakreditasi Aek Loba Kabupaten Asahan. Semakin tinggi tingkat jaminan yang diberikan kepada pasien saat berobat ke Puskesmas maka makin tinggi pula tingkat kepuasan yang diterima pasien saat berobat di Puskesmas (Aini dkk, 2016).

Emphaty (perhatian) adalah memberikan perhatian yang tulus sifat individual atau pribadi yang diberikan kepada para pelanggan dengan berupaya memahami keinginan konsumen, meliputi kemudahan dalam melakukan hubungan, komunikasi yang baik dan memenuhi kebutuhan pelanggan. Perbaikan rasa empati perlu dilakukan oleh seluruh ptugas kesehatan terutama para perawat yang menjadi ujung tombak dalam memberikan pelayanan karena selalu berhubungan dengan pasien dan keluarga. Diharapkan juga kepada pihak Puskesmas baik petugas kesehatan, petugas administrasi dan petugas lainnya agar dalam memberikan pelayanan tidak membedabedakan status sosial dari pasien yang berobat. Hasil analisis data ini menunjukkan bahwa empati pelayanan yang dinilai dari aspek kesabaran, keramahan dan kesopanan petugas kesehatan, kepedulian dan kemampuan petugas di Puskesmas Aek Loba menyelesaikan keluhan pasien serta memberikan pelayanan yang sama kepada semua pasien mempunyai pengaruh positif terhadap kepuasan pasien di Puskesmas terakreditasi Aek Loba Kabupaten Asahan.

\section{KESIMPULAN DAN SARAN}

Kesimpulan dari penelitian ini adalah seluruh aspek kualitas layanan yang terdiri dari aspek keberwujudan, keandalan, daya tanggap, jaminan dan empati berpengaruh terhadap kepuasan pasien di Puskesmas Terakreditasi Aek Loba Kabupaten Asahan. Dan aspek yang paling berpengaruh terhadap kepuasan pasien adalah aspek keandalan. Secara deskriptif kualitas layanan yang terdiri dari keberwujudan, keandalan, daya tanggap, jaminan dan empati di Puskesmas Terakreditasi Aek Loba Kabupaten Asahan sudah mendapatkan tanggapan positif dari pasien, untuk itu harus dipertahankan bahkan meningkatkan pelayanan yang diberikan 
kepada pasien agar Puskesmas Aek Loba Kabupaten Asahan yang sudah berstatus sebagai Puskesmas Terakreditasi dapat menjadi contoh bagi Puskesmas lainnya yang berada di Kabupaten Asahan dan lebih luas bagi Puskesmas di Propinsi Sumatera Utara dan nasional.

\section{DAFTAR PUSTAKA}

Aini Y., dkk, 2016. Analisis Kualitas Pelayanan Terhadap Kepuasan Pasien Berobat Di Puskesmas Pembantu Desa Pasir Utama. Jurnal Ilmiah Cano Ekonomos Vol. 5 No. 1.

Depkes RI, 2014. Peraturan Menteri Kesehatan RI Nomor 28 Tahun 2014 tentang Pedoman Pelaksanaan Program Jaminan Kesehatan Nasional. Jakarta: Depkes RI.

Depkes RI, 2015. Permenkes RI No 46 Tahun 2015 tentang akreditasi puskesmas, klinik pratama, tempat praktik mandiri dokter, dan tempat praktik mandiri dokter gigi. Jakarta: Depkes RI.

Depkes RI, 2017. Profil kesehatan Indonesia 2016. Jakarta : Depkes RI Jakarta.

Irawan, 2008. Manajemen Pemasaran Modern. Edisi Kedua, Cetakan Ke-tiga belas, Yogyakarta: Liberty Offset.

Lupiyoadi, 2006. Manajemen Pemasaran Jasa Teori dan Praktek. Edisi Ke 2, Jakarta : Salemba Empat.
Muhammad A, dkk, 2016. Hubungan Antara Kualitas Pelayanan Kesehatan Rawat Jalan Dengan Tingkat Kepuasan Pasien Peserta Jaminan Kesehatan Nasional di Puskesmas Siko Ternate. Pasca Sarjana Universitas Sam Ratulangi, Fakultas Kesehatan Masyarakat Universitas Sam Ratulangi.

Notoatmodjo, Soekidjo., 2005. Metodologi Penelitian Kesehatan (Edisi Revisi). Jakarta : PT. Rineka Cipta.

Pohan, Imbalo S., 2007. Jaminan Mutu Layanan Kesehatan: Dasar-Dasar Pengertian dan Penerapan. Jakarta. Penerbit Buku Kedokteran EGC.

Sastroasmoro, dkk, 2008. Dasar-dasar Metodologi Penelitian Klinis. Edisi ke-3. Jakarta: Sagung Seto.

Supranto, J., 2006. Pengukuran Tingkat Kepuasan Pelanggan : Untuk Menaikkan Pangsa Pasar, Jakarta, Rineka Cipta.

Trihono, 2005. Manajemen Puskesmas Berbasis Paradigma Sehat. Jakarta: CV Sagung Seto.

UUD 1945. Amandemen ke-2 pasal $28 \mathrm{H}$ ayat (1)

ValarieA. dkk, 1996. The Behaviorial Consequenses of Service Quality, Jurnal of Marketing,Vol 60.

Wardani, R., 2017. Analisa Kepuasan Pasien Ditinjau Dari Mutu Pelayanan Kesehatan Setelah Terakreditasi Paripurna Versi Kars 2012. Jurnal Wiyata, Vol. 4 No. 1. 